\title{
Honoring Our Heritage and Moving Ahead
}

The planning for the launching of the Journal of the Brazilian Chemical Society (JBCS) started in 1987 and it became a reality in 1990 with three issues per year. Continuous growing led to four issues per year in 1995, six issues per year from 1996 to 2005, eight issues per year from 2006 to 2008, then ten issues per year in 2009 and finally twelve issues per year starting in 2010 .

This evolution reflected the increasing number of chemical researchers in our community, producing good science, and the expansion of the graduate programs in chemistry and related areas, leading to an enhancement in the number of submitted manuscripts. In parallel, a consistent growing of international submissions occurred. The qualitative growing is also demonstrated by the JBCS impact factor reaching 1.00 in 2006 and 1.43 in 2011, even though the number of published manuscript had increased.

All journeys have landmarks and all history is supported by a group of visionaries and a supportive community. The timeline of the JBCS has clear evolution points: in 1995, it was indexed in most scientific databases; in 2001, the editorial office was moved to the University of Campinas; in 2004, it was set the online submission system with an open-access model and, in 2012, we started with the digital object identification, DOI number. Besides, the new cover layout that started in 2011 was well received by our authors and readers.

As in previous years, January is time for thinking about the work done in the preceding year and the plans to move ahead.

In 2012, the JBCS received over 600 submissions of scientific papers and a total of 280 articles was published in 12 issues.

Compared to the 2010-2011 biennium, the publication of foreign authors was smaller, representing $15 \%$ of the total articles published, even though the number of submissions from abroad has been exceeding domestic contribution. Iran, China, India, Colombia, Turkey, Pakistan, Chile, Egypt, Mexico and Serbia were the countries with higher participation.

These data reflect that we are able to mobilize the Brazilian scientific community and so we are achieving one of the goals of the JBCS, which is the dissemination of the research in the Chemistry developed in Brazil.
Although it is clear the chemistry scientists' community's interest in publishing in JBCS, we are experiencing high rate of rejection of articles. Unfortunately, many submitted manuscripts lack adequate preparation, ignoring the rigor necessary to meet the standards of international journals.

As one of the results, the processing time involved in handling manuscripts may be delayed. Efforts have been devoted to decrease the time of online publication, yet the average 5.5 months obtained for 2012 remained very close to the value of 5.4 months for 2011.

We must remember that a manuscript processing involves multiple steps and actors. In addition to the editorial office, editors, authors and reviewers are critically involved with the processing of submissions. The agility in processing manuscripts depends not only on the journal staff, but also on all authors and reviewers.

Compared to the data for the period between 1997 and 2010, there was a significant increase in the number of articles published in the field of Analytical Chemistry for the biennium 2011-2012, while the number of publications in the areas of physical chemistry and inorganic chemistry decreased. These data, although preliminary, indicate a trend that should be monitored, since JBCS intends to disseminate results of original and significant contributions of all areas of research in chemistry, with the exception of education, philosophy and history of chemistry.

What about the future? What should we expect for this coming year? The main novelties for 2013 are the start of a new online system integrated with the ScholarOne - Scielo and changes in the JBCS Editorial Board.

The new online system ScholarOne - Scielo offers an option of software for editorial management for periodicals being part of Scielo, as a partnership with Thomson Reuters. The ScholarOne was founded in 1999 and was incorporated by Thomson Reuters in 2005. Nowadays, ScholarOne have around 5,000 journals and 13 million of users.

There will be no additional costs for the JBCS and the proposal is to adopt a state of the art platform for management of online submissions and reviewing of manuscripts. The ScholarOne has an exclusive area for sending suggestions and ideas and all of them are discussed by the users' community and further adopted if broadly supported. 
As announced in December, 2012, ${ }^{1}$ another major change will be the departure of two editors that have participated since the first discussions to create the JBCS. Two of our "Founding Fathers", Angelo da Cunha Pinto e Jailson Bittencourt de Andrade, are leaving.

On the one hand, we all know that they accomplished their mission with merit and showed us how to keep moving ahead. On the other hand, we all know how much we will miss them and all their permanent guidance and companionship.

We certainly agree that "the consolidation of the JBCS is a result of the efforts, dedication and commitment of its ex-editors, of its current editors and associate editors, of its authors, of its reviewers, and of the JBCS and SBQ staff... We have confidence that we are on the correct path, in the continuing search for excellence for JBCS." ${ }^{2}$

Be sure we will be extremely careful to follow your footsteps, experiences and example of dedication that you both gifted us. We will keep alive the dreams and the achievements of the JBCS. ${ }^{3}$ We do know, Angelo, that "making dreams come true requires, first of all, will and action" and we agree that "with work, courage and intelligence, Brazilian education can be changed." ${ }^{4}$ We will never forget that "Beauty, Science and Arts are Siamese sisters... Science is a great adventure, which should be experienced in its fullness. And as any adventure, it is beautiful for those who give themselves to it body and soul." 5

It is amazing how the time goes by. Recently, we were chatting with Jailson and he told us about his 25 years of experience with the JBCS. It is a long journey. History was made. From the always risky beginning to nowadays, the JBCS has become a major scientific journal in the international scenario and major challenges were overcome, such as its periodicity, financial support, visibility, and the increase of the number of published papers without decreasing its quality.

We do express our gratitude to Angelo and Jailson, who, together with a strong and effective group of hard workers and a supportive community from all fields in chemistry, have dedicated their best efforts to the development of this editorial project, which is a landmark of the Brazilian Society of Chemistry. Part of this hard work has also led to our successful journals Química Nova, Química Nova na Escola and Química Nova Interativa. No doubt, Angelo, Jailson and the group of Editors have foreseen the future and the JBCS option to open electronic access was an important step towards the broad dissemination of a science without borders. ${ }^{1}$

Indeed we will do our best to keep this successful track with the permanent and fundamental support of all authors, reviewers, readers and the financial support of the Brazilian National Council of Scientific and Technological Development (CNPq) and the São Paulo Research Foundation (FAPESP).

Last year, the Brazilian economy coped with uncertain times and 2013 will not be a smooth road, but we must keep our goals towards a Brazil economically powerful, with an educated population and with great possibilities for every citizen to develop their full human potentials.

The recent decision to apply in education the future royalties collected from oil production contracts under the concession regime signed for production in areas outside the pre-salt, Provisional Act 592/2012, is an important path towards our critical needs in educational area. The Provisional Act 592/2012 states that the application of these royalties for education will be additional to the minimum required by the Constitution.

It is important to emphasize that the country must be ready "for the XXI century agenda, which requires focus and investments in innovation, sustainability and interdisciplinarity. This trinomial will only become possible with the strengthening of the connections of Science with Education and of Science with Technology and Innovation". ${ }^{6}$

We wish a wonderful 2013 to everybody and full success to all of us in our new endeavors and challenges.

\section{Joaquim A. Nóbrega JBCS Editor Vanessa Hatje JBCS Associate Editor}

\section{References}

1. Pinto, A. C.; De Andrade, J.B.; J. Braz. Chem. Soc. 2012, 23, 2131.

2. Loh, W.; Dias, L. C.; J. Braz. Chem. Soc. 2010, 21, 2.

3. De Andrade, J. B.; J. Braz. Chem. Soc. 2009, 20(1), iv.

4. Pinto, A.C.; J. Braz. Chem. Soc. 2012, 23, 1410.

5. Pinto, A. C.; J. Braz. Chem. Soc. 2012, 23, 1578.

6. De Andrade, J. B.; J. Braz. Chem. Soc. 2010, 21, 1594. 